\title{
IMAGE OF THE ABSENT
}

\author{
Ayellet Ben NeR \\ Translated By Ella Levenbach
}

\section{INTRODUCTION}

Image on the Absent, which might be described as a fictional life writing, seeks after the right assemblage of visual qualities that can depict a persona. This project exists in its Hebrew version in the Tel Aviv Museum of Art library and was exhibited in Sifria Balayla (Night Library) (Jerusalem 2014) and in the Artport artists book fair (Tel Aviv 2014). The project is inspired by notorious Adolf Eichmann, here a protagonist exploring his own image through self-revelatory confessions. These confessions are received and reproduced by a female sex worker. The English translation of the project was made by Ella Levenbach. Thanks are due to Yad Vashem, World Center for Holocaust Research, for permission to reproduce many of the images used in this piece.

EDITOR's NOTE: Some images from "Image of the Absent" have been removed pending copyright permission for this online English edition. This work will be updated as permissions are obtained. 
[Approval to use image pending]

\section{Image of the}

\section{Absent}

A Prologue / An Elegy 
A slight floating sensation, which seemed to affect the actual presence of objects, people and even the air around me, accompanied me for days after I first met with $E$. It probably had to do with a strange feeling, which crystallized at some point between the middle of our encounter to its end, that I knew him. It made no sense of course - he came from a different country, his mother tongue was a language I spoke no word of, and the culture he grew up in was foreign to me - at least that's what I thought at first, when I took a glance at the book shelves in the guest room of his home, at the ornaments, at his meticulously tailor-made clothes. On second thought, that first glance may have been the moment of déjà $\mathrm{vu}$, a sense of imaginary familiarity from the past. But as time passed this feeling became so strong and so real that I could complete his sentences, furthermore, I knew, even after a long silence, what he would say when he began talking again, without asking anything or interfering with his stream of thought in any way. At this point it felt like watching a movie based on a beloved book - one becomes so excited by seeing the details, words, and sentences, as they create a familiar meaning in a new and surprising way; slight disappointment from the reduction of grand ideas and vague abstract feelings into concrete details; and an anticipation for it to go on and on. I didn't know which one of us held the wondrous ability to create this dialogue between us, in which every word pronounced into the room was nothing but an echo of a previous thought that seemed to be echoing another thought, and another one, into itself. Was he endowed with a rare talent to make the person opposite him feel as they have known each other for years, or had I entered a state of mind that enabled me to read the person opposite me?

But as time went by things became clearer. I am presenting his story as he told it to me - in fragments, not chronologically. The general continuity is occasionally disrupted by my reflections. 
Ben Ner 
Persona Studies 2015, 1.2

The child is father of the man 
Ben Ner 


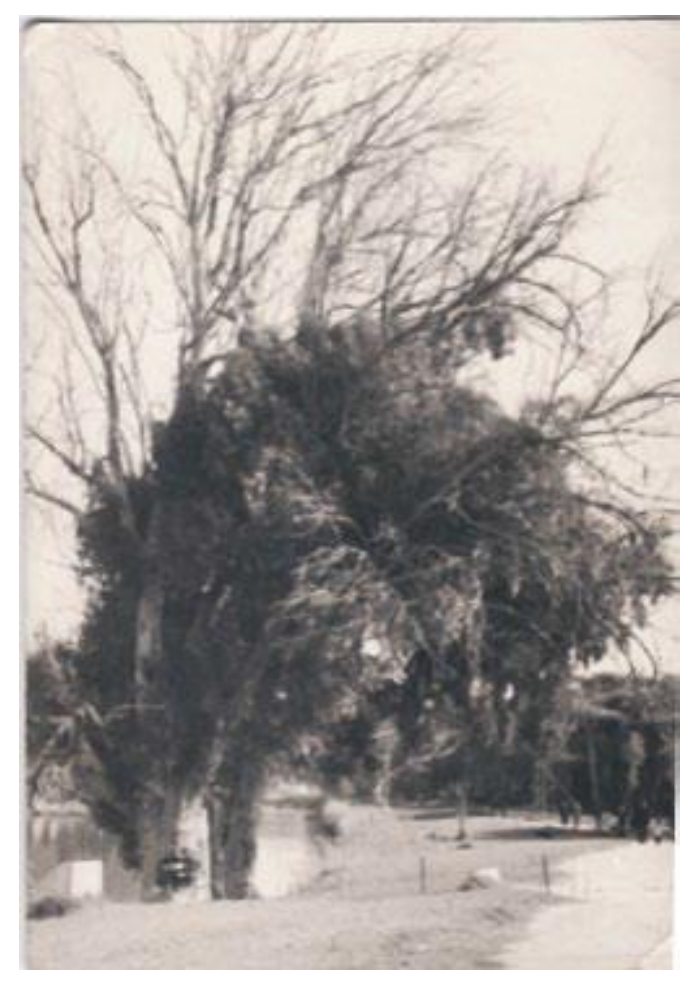

Fig 2: Author's Private Collection

Until the age of 56, the thought of settling down in a place like Israel didn't even cross my mind. I had visited the area, but it was on a business trip, even though I had some personal interest in the residents of what then used to be Palestine and their way of life. I remember that when the ship sailed from the Haifa harbor and someone beside me said "It's good to be going home," I nodded in consent to myself and didn't pay any attention to the notion of what might happen if one day $I^{\prime} d$ have to live here. So when, on a flaming August day in '87, I found myself in the blazing hot, unair-conditioned office of a Nazareth garage waiting for one of the boys to finish working on my car - which turned out to have a worn out axle seal- I asked myself what the hell I was doing here and how I got here. For a moment it seemed to me that the time since I had last seen the waters surrounding the western beaches of Israel, at the age of fifty six, had gone by while I was asleep. It wasn't just the heat that led me to these thoughts, which would seem illogical to me at any other time; and it wasn't only the fact that the office I was waiting in had no air conditioning, just a ventilator that was merely pushing the soot of the cars back outside and not cooling the air at all, it was also a phrase from a Wordsworth poem I had stumbled upon when paging through a pile of newspapers on the small table that separated me and the other waiting men: 
On my way home, I almost crashed into a white car driven by a young woman. When she looked at me, overwhelmed with shock, after I had brought my newly repaired car to a screeching halt, it looked like she recognized me - or maybe it was the mutual proximity to the moment of a crash that awoke a sense of identification between us. At the end of the side-road that led to the Moshav ${ }^{1}$ I was living in at the time, just a few minutes away from my home, next to the secretariat and the post boxes, I decided to park the car and walk home. I remember how completely foreign I felt during this walk. I imagined myself as a prisoner whose cell borders are defined by the walls of the houses protruding among the well-groomed gardens around him, and all he can do is imagine the freedom hiding behind those walls: the small objects decorating the kitchen and living-room shelves, the rows of books standing on the bookshelves, the pattern of the material covering the chair seats, the pillows resting in a pleasant and orderly fashion on the couch and the silent figure sitting on it, in a room that is always dark.

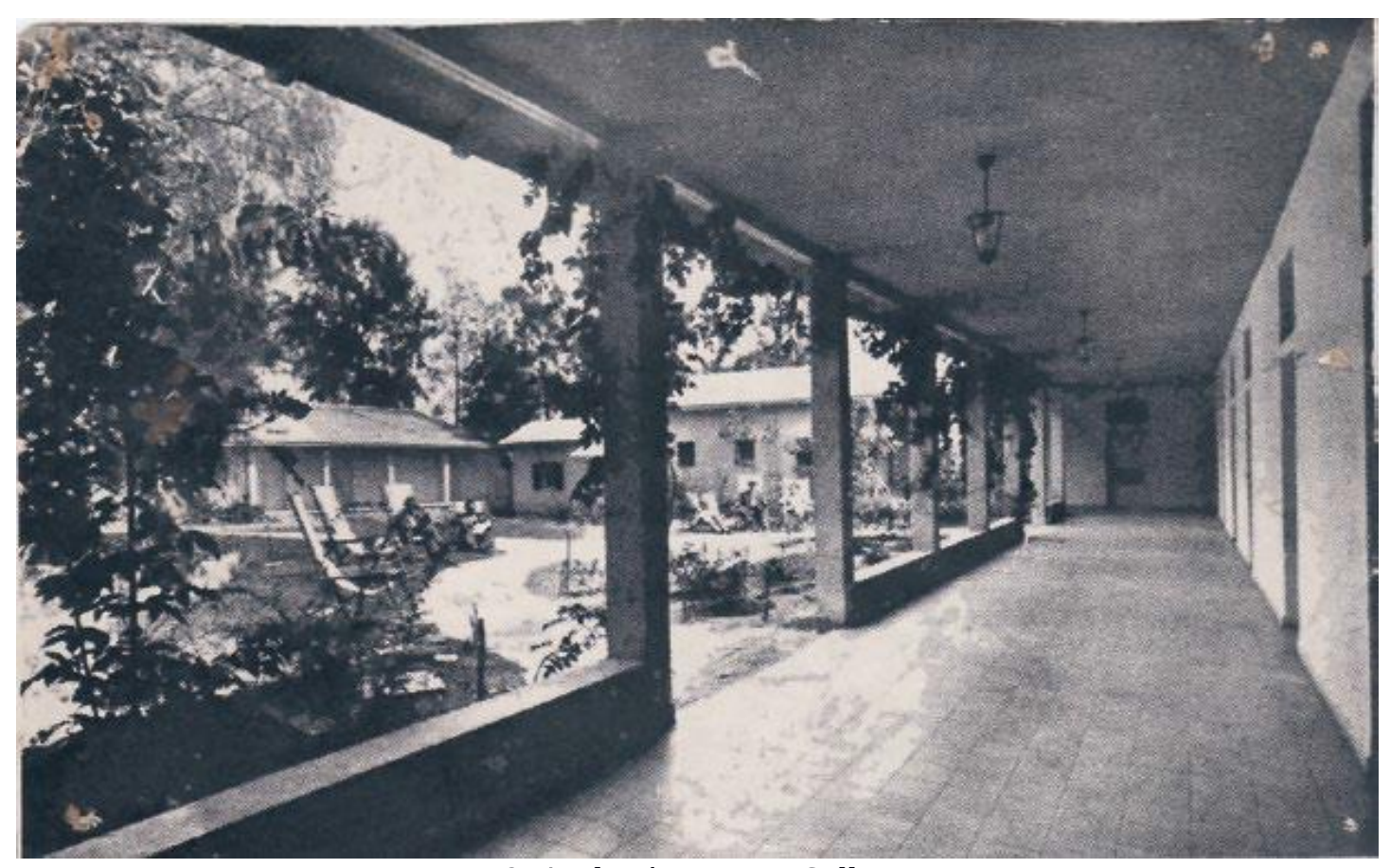

Fig 3: Author's Private Collection 
Later that day, at home, as the last residues of yellow-gray sun rays came through the window and the thick heat began sinking into the asphalt, I went through my belongings hoping to understand the essence of the strange events that had been happening since that morning, or to find a memory that seemed to be lost. I came across a triple photograph of Harold Lloyd with a double caption from a book about the history of the silent movie. Lloyd's arms look like stumps. Somewhere I read or heard that the voice was taken from the silent movie stars and so they are doubly doomed to suffer from the photographic "unconscious": the phenomenal ability to separate identity from image, to plant a type of split personality in the person who is being filmed from the moment the shutter closes and his image is imprinted on the film. It's double because every person has flipped through a year book and looked at graduation photos: even (and maybe especially) when you yourself are photographed in them, a foreign feeling accompanied by wonder arises in you the more you look at the photo, until your body seems to detach from the gazing eyes and is absorbed into the infinite void of time that slowly grips you from within.

Fig 4

[Approval to use image pending] 
"Harold Lloyd when his face was covered with almost as many freckles as there are grains of sand on the shore; and they didn' $t$ wash off with the tide, either."

"Harold Lloyd as he is not. He's not the 'pretty pretty' fellow the photographic 'art' retoucher has made him, but a wholesome, big boy, in a rough tweed suit and a radiant smile".

This void had begun covering my consciousness like termites feeding on a tree, when the sentence re appeared in my mind:

Des Mannes Vater ist das Kind

and with it the understanding - or the feeling - that took hold of me that morning, and seemed like a passing circumstantial issue at the time, only strengthened and intensified until the piles of books surrounding me came to resemble a tombstone, prematurely carved just for me. 
Persona Studies 2015, 1.2

You are born every day but

Your legs are as heavy as

Your father's and your father's father

Who was murdered just outside the woods

Zrubavel Gilad 
Ben Ner 
The similarity between us grew and expanded and as $\mathrm{E}$ delved deeper into his stories I found myself discovering and rediscovering this amazing ability to instantly connect with no common history, biographic details (of which I knew very little), origins or anything else that could separate two people or bring them together. It may have been infatuation his character caught me by surprise, when I wasn't ready, and revealed itself to me in various places and in unexpected contexts. It suddenly emerged on the TV screen, when I was watching a program on the Dada movement; it appeared in my mind's eye while I was busy separating the white laundry from the coloured, although at that threatening moment, his face was blurred and looked like the face of a different man who I probably remembered from my past, without knowing his name or even remembering where we met.

Fig 5

[Approval to use image pending]
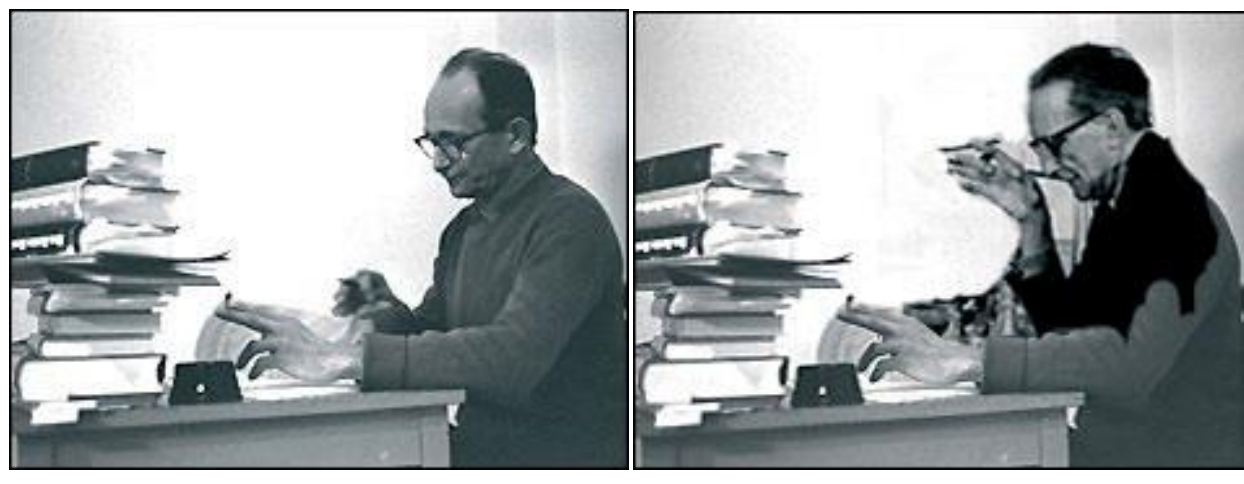

Fig 6: Courtesy of Yad Vashem 
He also emerged, suddenly, out of a page from a book written by Sebald who describes an adolescent dream he had about the "Americanization of his personality" which was soon replaced with an "aversion to almost anything American" - and while I looked at the accompanying picture, which was used to support the incompetent words, I suddenly noticed the faces of the two women, as if they were not there before. They were sitting on both sides of the spectacled man who awakened the image of $E$ in me - both facing him, and at the same time ignoring his existence and passing an imaginary object between them, as though he isn't present between them at all.

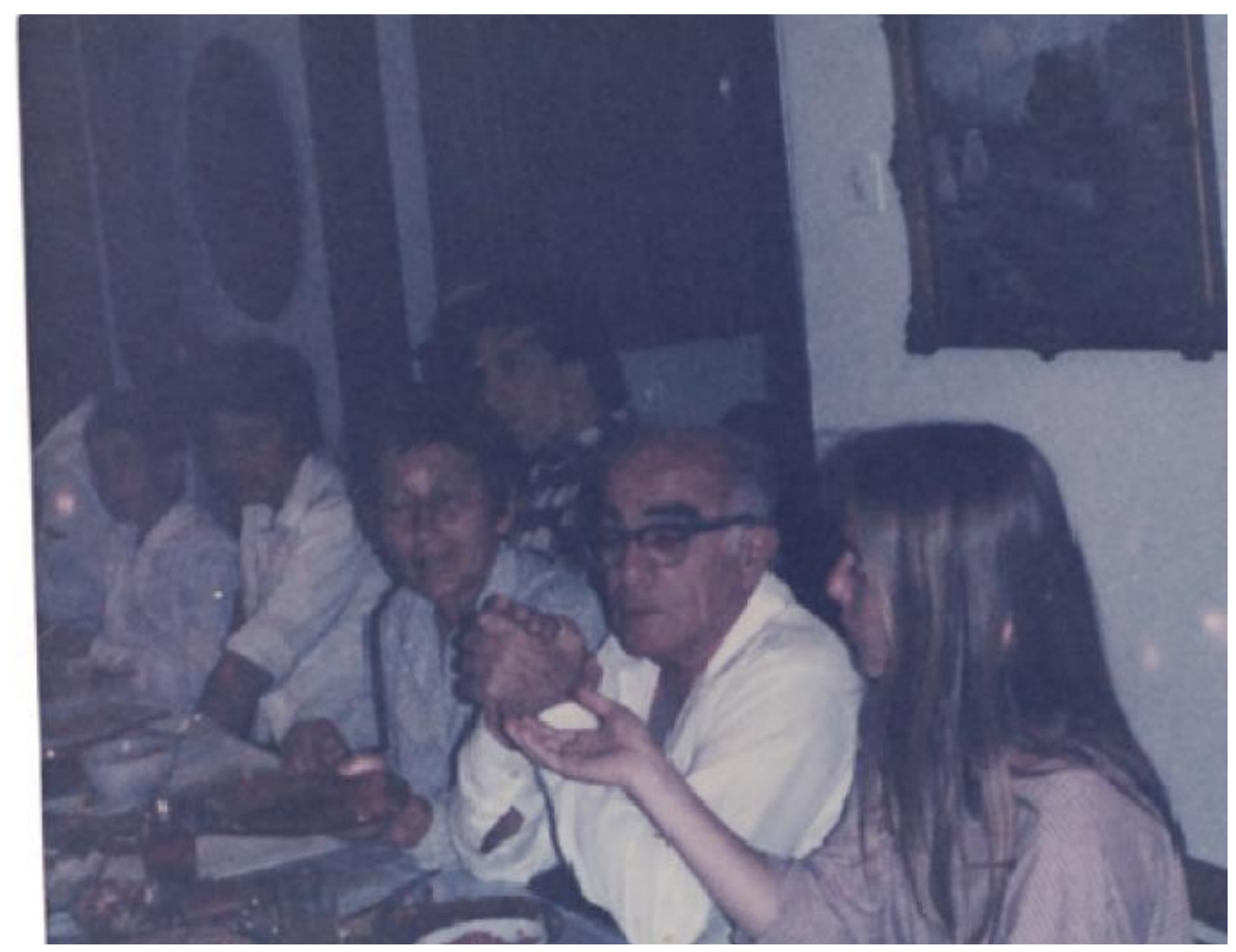

Fig 7: Author's Private Collection 
In any case, the conversations and meetings continued, not always of my own accord - he would call and ask me to come over, and I would come. Every time he called I thought I could hear the hesitation in his voice, it may have been fatigue or fear of rejection. These voice signals, the possible feelings that broke through the formality of the actual words and became a visible conflict, led me to think or believe that he knew, better than me, what has to be done, what the right agenda for the day was and how things should take place but that something prevented him from expressing himself confidently and with resolution - and I was to understand the Intent behind the words and bridge the gap. After my arrival, during the long conversations that preceded the sexual encounter, he tended to jump from one topic to another. Only a slight associative link connected between the subjects (this led me to momentarily suspect that some hidden disease may be wreaking havoc in his brain). He wondered melancholically about the meaning of his life and life in general. 
Where am I present? Where have my shoes made their mark, where have my fingers left their prints? I am like those ghosts that emerge from the photograph of a disaster or fatal accident: after it's developed one can identify a human shape in the corner: he is walking towards the photographer, as though his feet are stepping on a plain different to the one the photographer and those photographed are standing on, almost as if he is floating but at the same time determinately advancing towards a clear goal or driven by an inherent power of movement he cannot stop.

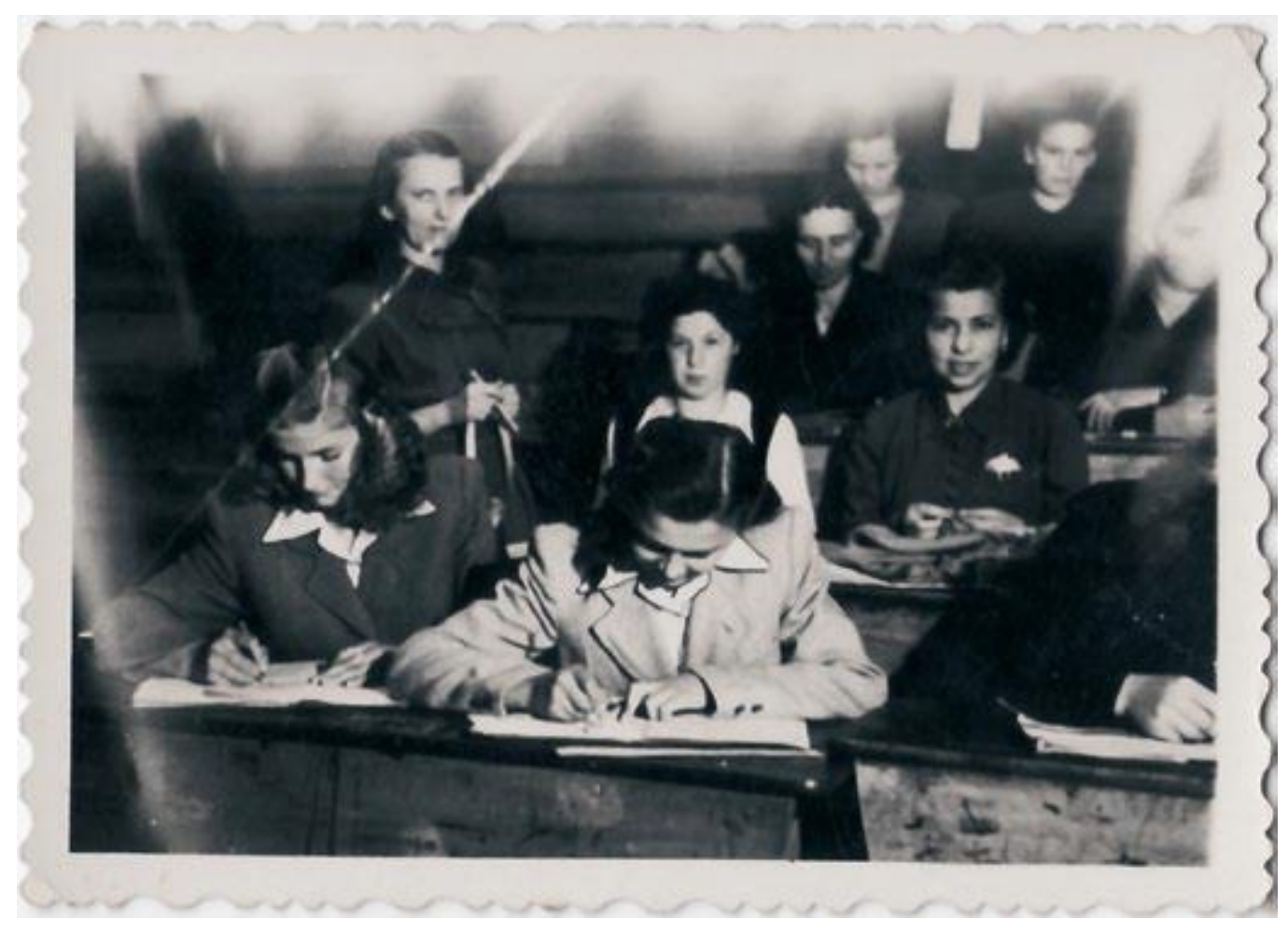

Fig 8: Author's Private Collection 
During one of our meetings, he showed me four photographs he held before going to sleep: three of them were from books and newspapers and the fourth was a photo of him. They caught his eye, so he claimed, absent mindedly - but he found the similarity between them in full awareness:

Figures $9 \& 10$ [Approval to use images pending]

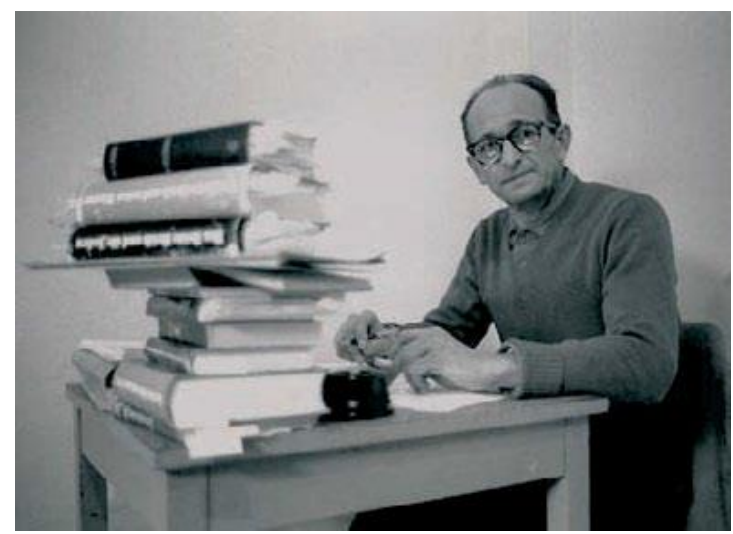

Fig 11:

Courtesy of Yad Vashem
Fig 12:

[Approval to use image pending]

\begin{abstract}
Although each one was taken in a different location and probably at a different time, in all of them the eyes are startled, exposed and looking at the camera, so he said; the hand is holding a pen or carelessly resting on a typewriter as if we were all caught in flagrante delicto. After some reflection, during which we were both silent,
\end{abstract}


he took out the whole photo album--an act that usually suggests romantic intentions but not with him. It seems that the soul to soul connection was the drive behind his actions and introspection. Paradoxically, as the introspection revealed itself to me, he became more distant from himself, as if he was examining himself, trying to discover the objective truth, not a subjective proximity that can fake itself. When he paged through the album, he made a kind of general comment that could equally have been made in an introductory class to visual culture. He said the person photographed is characterized by the context of all elements - the light, the age of the picture, the quality of the photo, its surroundings, the different events the picture exposes, including the random ones. My identity may derive from the way I look at things, he offered suddenly and raised his eyes to me, but then he returned them to the picture that was lying in front of us at the time, said something and continued paging, every picture received its own explanation and interpretation. 
Persona Studies 2015, 1.2

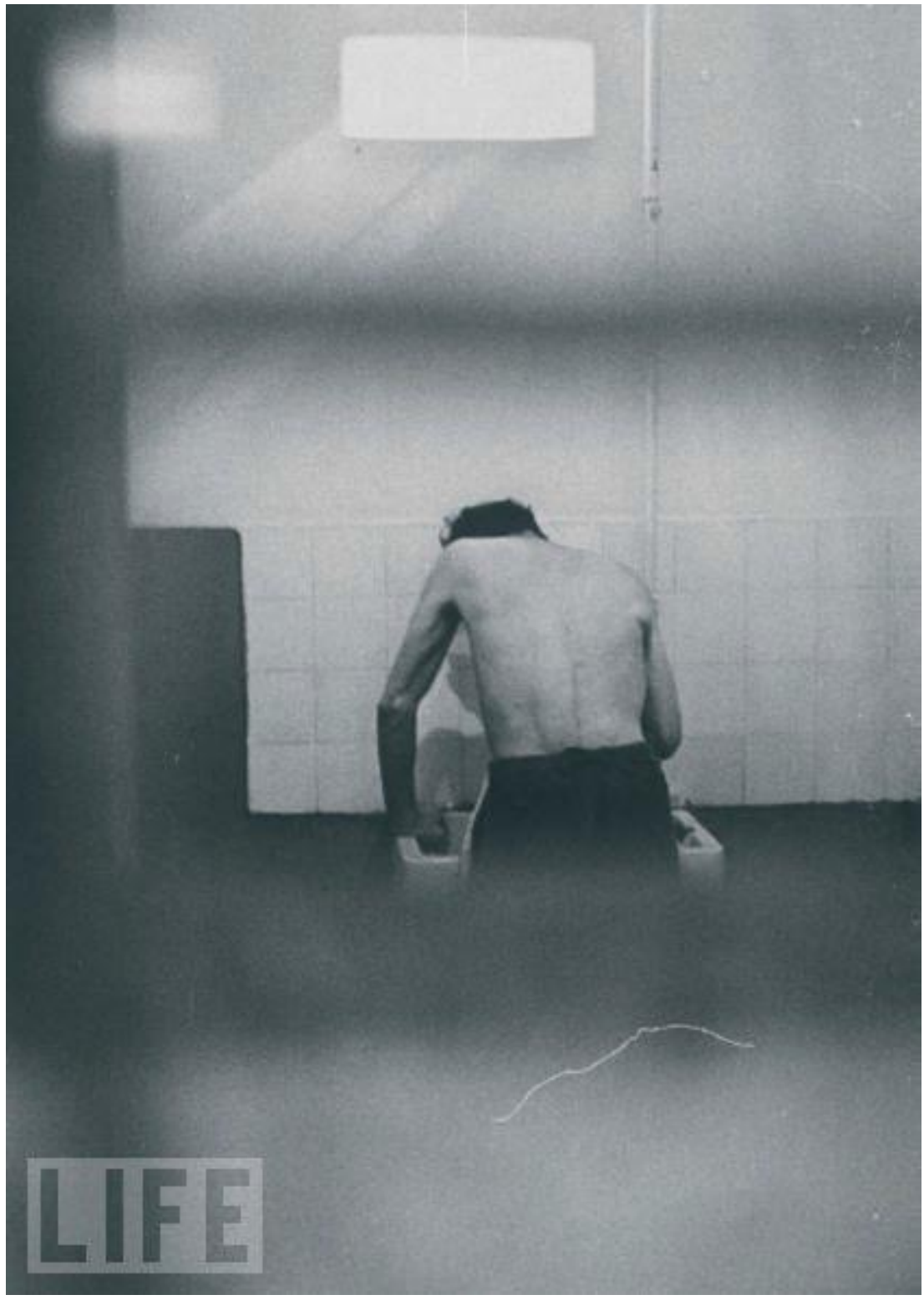

Fig 12: Courtesy of Yad Vashem

The film is scratched; the double square of light is the complete opposite of my spine. 


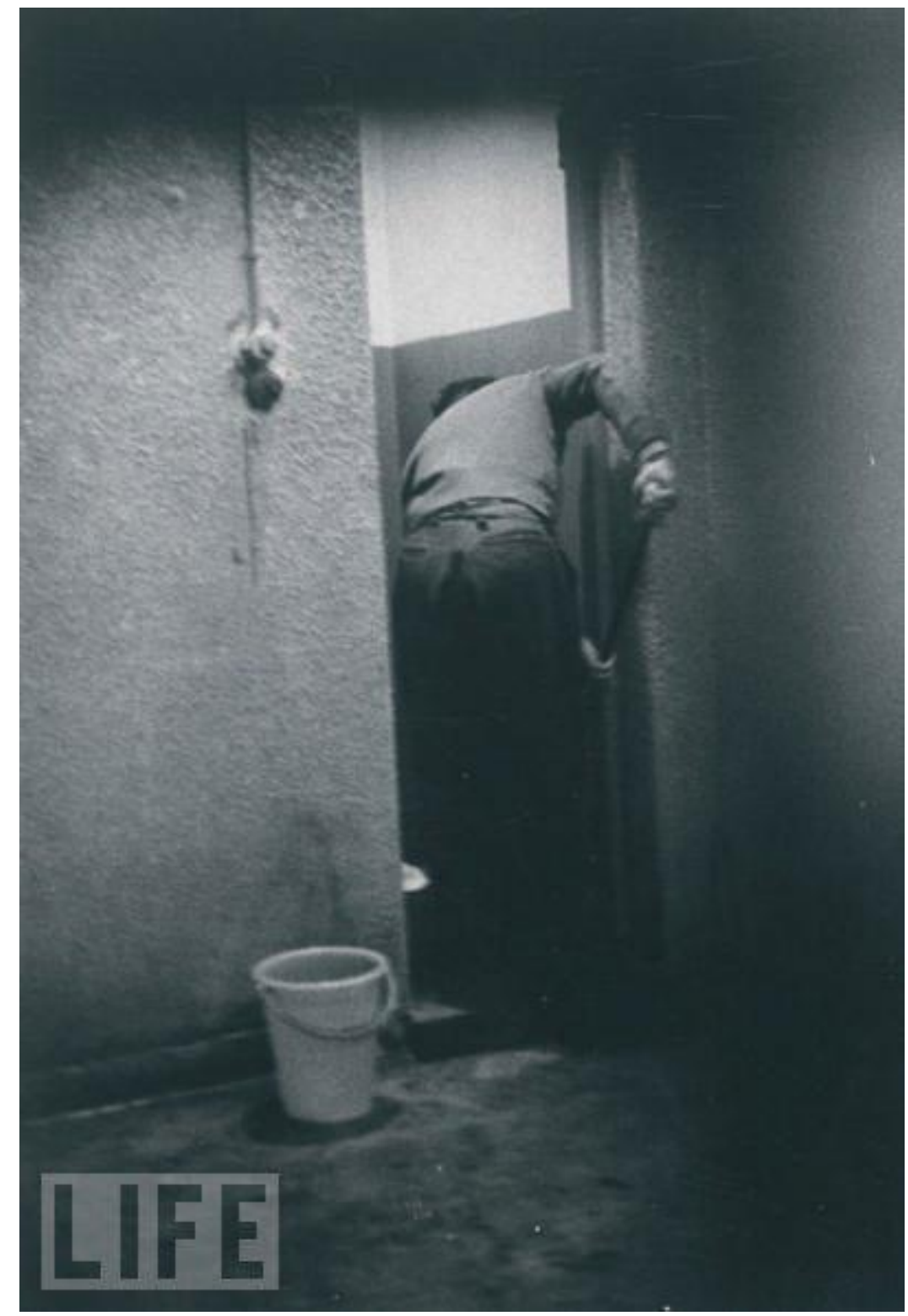

Fig 13: Courtesy of Yad Vashem

\begin{abstract}
Black Thursday - cleaning day. From the ceiling, from the same dark grid that encloses the photograph and blurs its borders, grows a strange black upside-down flower and the line of colour on the small cell, which for some reason looks like a bathroom to me, challenges all rules of logic. It reminds me of an illustration from the Little Prince - he is wearing green, digging in an enclosed volcano, his figure is disproportionately large and around him slanted flowers grow from the ground like the pine and maple trees that grow in Japan.
\end{abstract}


Persona Studies 2015, 1.2

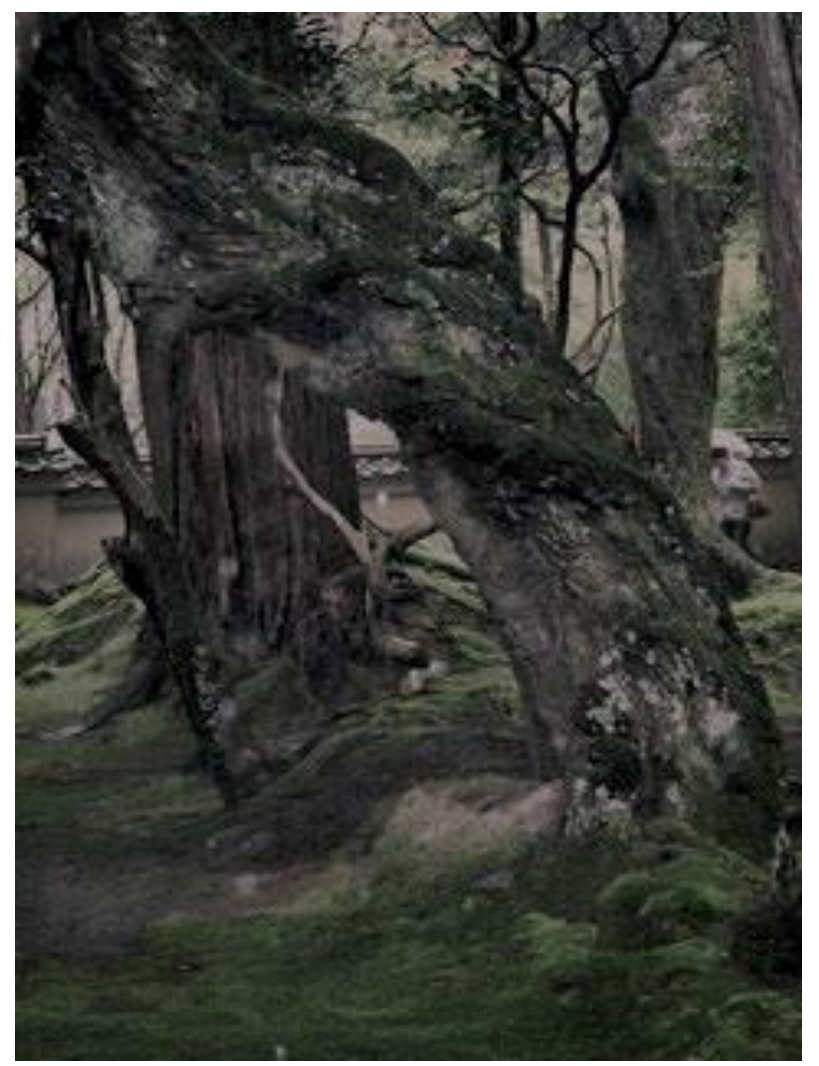

Fig 14: Author's Private Collection 


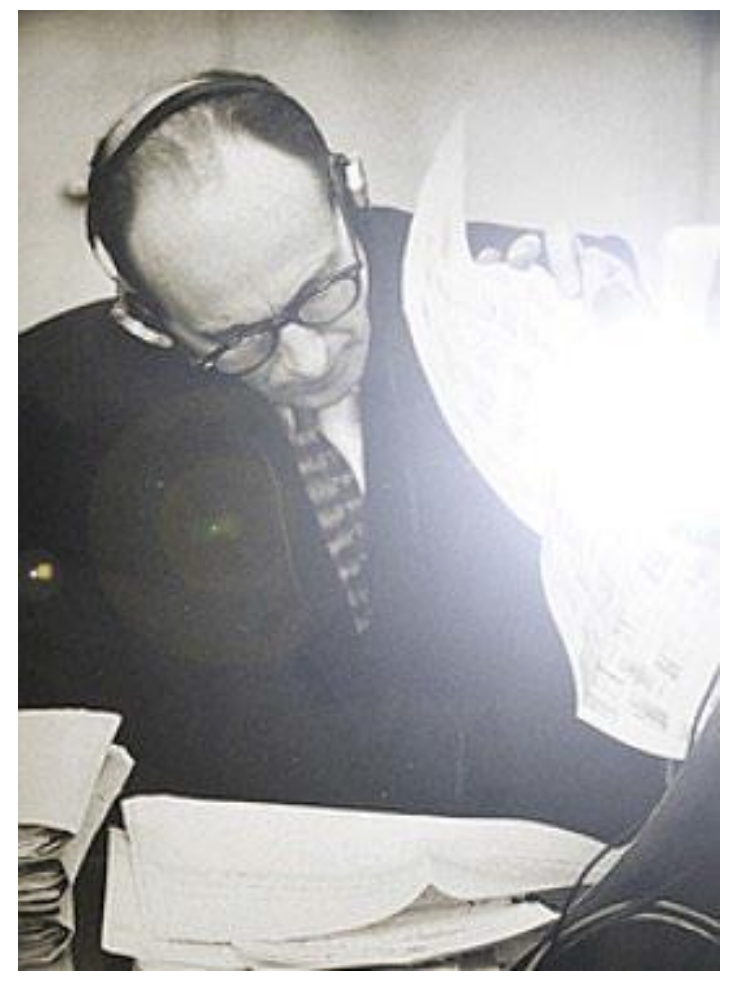

Fig 15: Courtesy of Yad Vashem

This photo was most probably taken in a library. It must have been the early ' $60^{\prime} \mathrm{s}$, in Jerusalem, adjacent to that significant and transformative event - it looks like a depiction of the moment of revelation, like the one Saint Hieronymus had.

The pages project a sacred aura that is about to reach the person looking at them (or clinging to them) and will inhabit him for eternity. In Caravaggio's painting it is already a permanent inhabitant above Jerome's head, who continues clinging just for the sake of the action in itself.

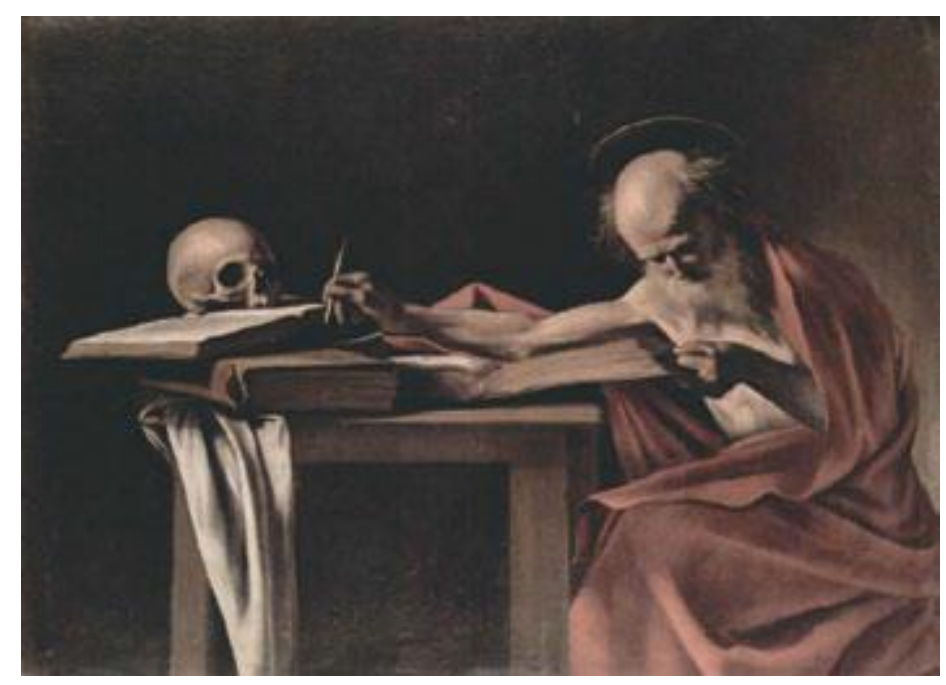


We are so immersed in the text that is lying in front of us that we forget the close presence of death.

He who is adhered to the aura is not part of the chronological time continuum and has no influence on what is part of that continuum, $E$ argued. If he did so in order to justify an existential fallacy or for some other reason, I could not understand. It's a nice way to avoid the question of whether the Scriptures are testimony or myth, but every text that projects an aura on its reader becomes holy and every act of reading during which direct contact between the text and its reader takes place, becomes a transformative one. Thus the acts of reading and writing become timeless opportunities, instead of taking on their regular role - creation or confirmation of testimony or myth. When describing a timeless occasion of this sort, the face is not revealed in order to neutralize the chronological time continuum set by a subjective approach. Events that involve hiding or revealing of the face always carry within them a defining moment that deviates from the time continuum and stays hanging in space forever.

He also said: memory is a phenomenological structure, he said; it builds itself.

So said E. 
Ben Ner 
This photo, which he gave me as a memento and didn't say much about, also lay in the suitcase under his bed, in the same pile of papers, photos, and other personal documents he showed me, a little at a time. I was born on the $19^{\text {th }}$ of March 1906, he said again and again, in Solingen, North Rhine-Westphalia, and came to Israel at the age of 56. If I were forced to guess the circumstances in which this photo, which he didn't expand on, was taken,

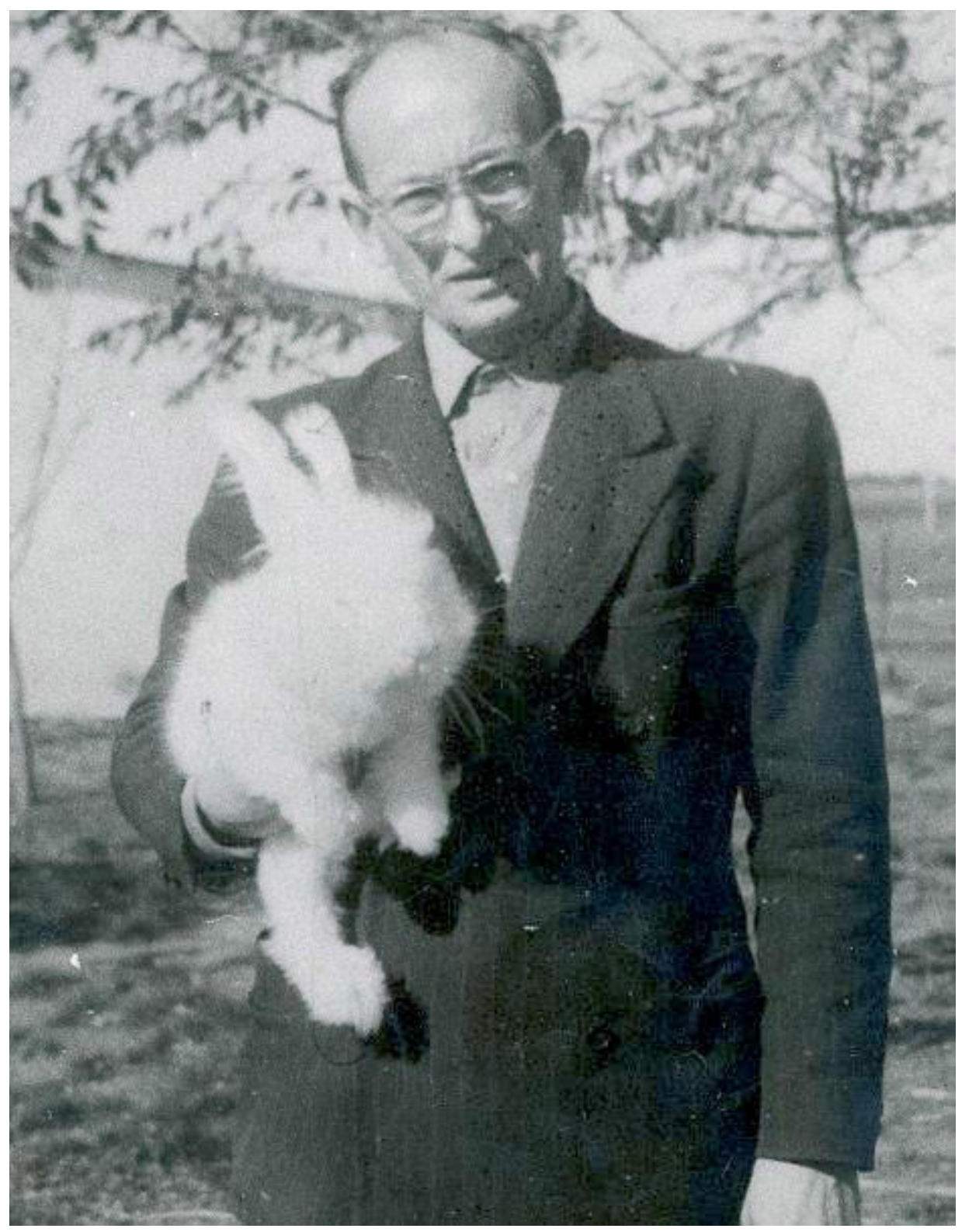

Fig 17: Courtesy of Yad Vashem 
I would say it seemed as though he was visiting friends he hadn't seen for a long time and they were pleading with him (it is evident in his expression) to be photographed in their garden as a memento. On the right, his left, I guess, stands their two- story home with a basement where they keep and age wines made from grapes picked in the vineyards surrounding the house - it looks like there's a wide territory behind the house and the photo is too blurred and old to show the actual vines. Their image isn't present in the photo and, I am not confident it was a couple and not, say, an acquaintance or a distant relative who invited him to spend a weekend in the country. I imagine that not only grape vines grow there, but also herbs, tomatoes, garden plants like Tagetes and Bougainvillea and even some well-fed animals that grow to impressive sizes, like the rabbit he is holding and seems to be asleep. But the circumstances of the photo don't explain the fact that the horizon on the right is higher than it is on the left; that the shadow, which also falls only on the left piece of land, indicates that there is some kind of structure on the photographer's left and E's right; and that the slanted object that seems to be coming out of his neck and looks like a bone of a human or animal bone, cannot be satisfactorily explained as a branch or awning and is situated in a way that defies gravity. A more profound and longer look brings to mind that the figure itself splits the photo into two. If I shut one eye, just as he is doing in the photo, and hide the floodlit plain on the left with my index finger, I see before me a figure fit to be in a conference hall, as one of the highly influential participants, or in a concert hall, as the orchestra conductor. And when the shaded part on the right is covered, the character revealed reminds me of the children who can be found in any photo album - their discontent silenced by a pet or some game they are forced to present to the camera and they obey in horror of the moment, out of the sheer loneliness forced upon them when the face of the adult opposite them disappears and is replaced by the camera, which warps the moment in order to document it. According to all calculations, he is no more than 50 years old here. He holds the sleeping rabbit, which is completely unaware of what is happening, as a shield that separates him from the camera, the photographer, and the future viewer of the photo. He has not even the slightest suspicion that one day the eyes falling upon the photo will be his or mine. 
The last time we met - it was May of 2001 if I am not mistaken, when Saturn, the great mentor, entered my star sign - he said he thinks that radical changes are about to take place in his life and he prefers not to be caught unprepared, and so, he is leaving. Then, I believed that a transformation had occurred in him, something I had missed and maybe could not be fully explained between two people, but things he had said to me in the past suddenly took on a deeper meaning, as if the separation suddenly revealed a whole new part of him that I hadn't noticed until then. When I thought about the things he had said about transformation and the endless split between the external and the internal, it looked more and more like he had foreseen what I could not predict: the moment of departure. Whether he knew what was about to happen - that he would have to leave (he said nothing to me) and was afraid to tell me, and whether he hid it from himself as well or not, he left hints of the fact that his presence here is only temporary and that his future image was destined to collect more and more meanings in my memory until at some point, some arbitrary moment in time, when enough blocked and unsolved memories will be assembled, we will become the same person.

So departure is necessary in order for transformation to occur and it marks the end of fragmentation. Later, when I departed, and left images and stories behind, I also avoided the same occurrence which could catch me ill prepared. And as I write, the assemblage of meanings grows, the memories pile up, and the arbitrary testimonies of my existence receive a life of their own. 
Ben Ner 
Persona Studies 2015, 1.2

Has anyone noticed the difference between the young Adolf Eichmann and the person presented as Adolf Eichmann at his show-trial?

The original Adolf Eichmann:

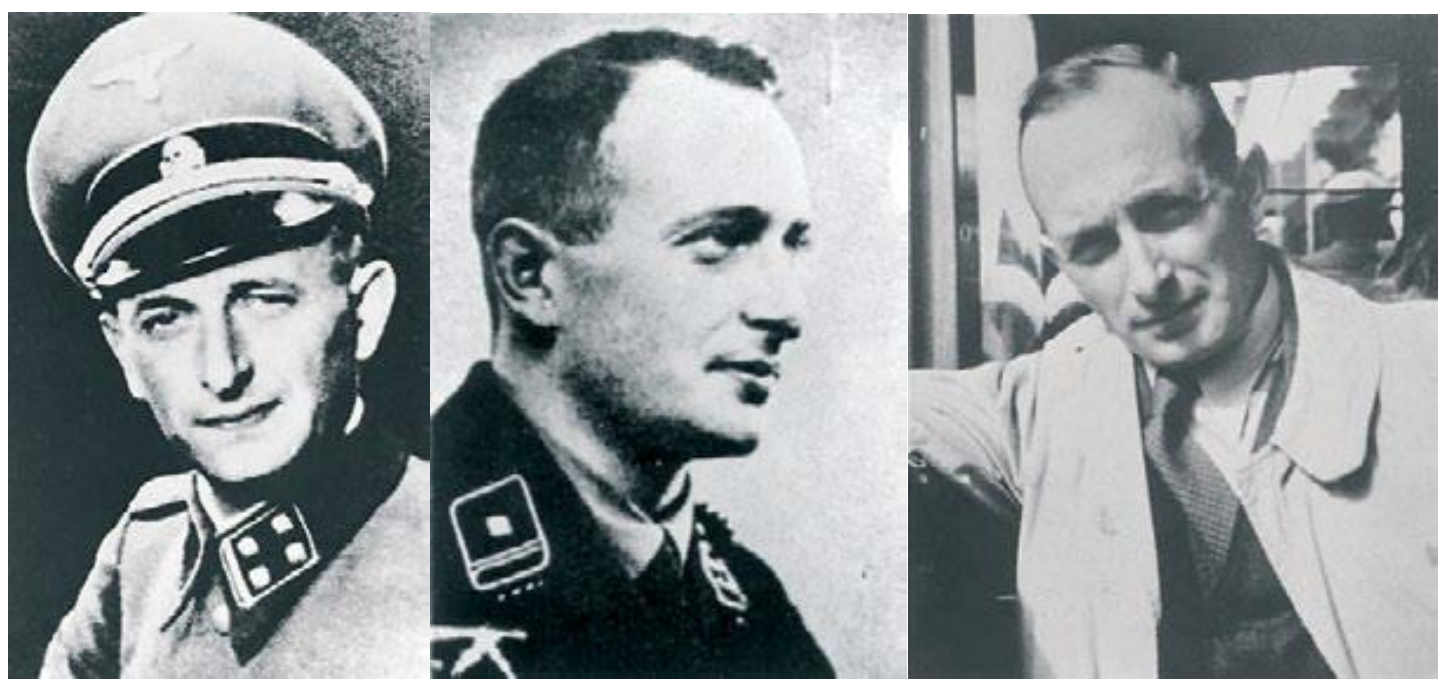

Figures 18-20: Courtesy of Yad Vashem

And

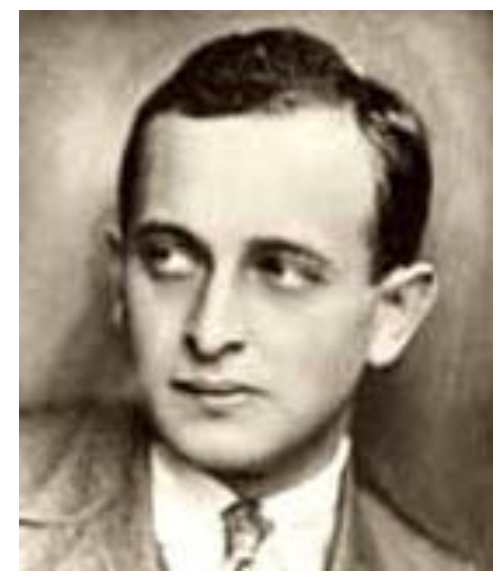

Fig 21:

Courtesy of Yad Vashem 
Ben Ner

The "Eichmann" on trial...
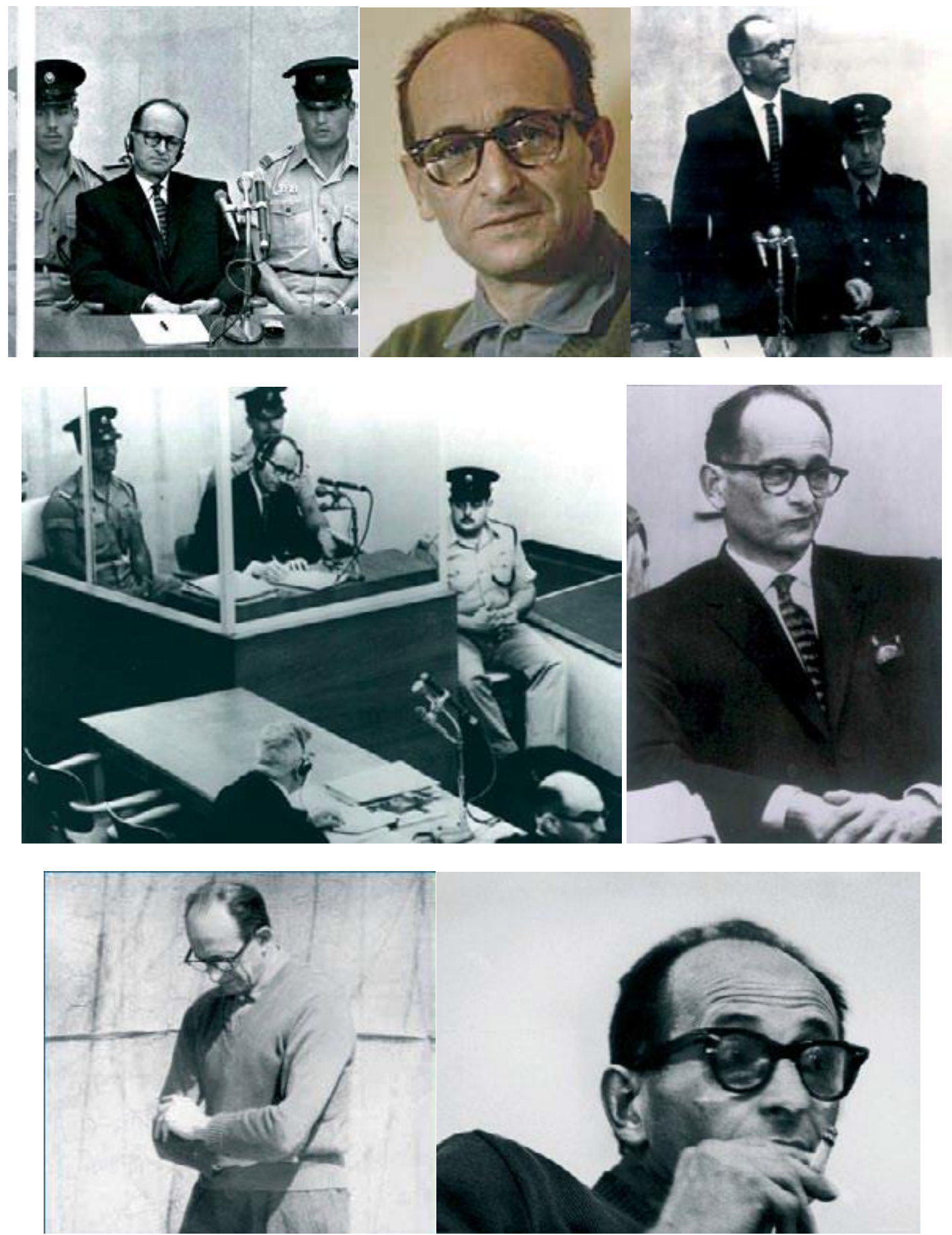

Figures 22-28: Courtesy of Yad Vashem 
Clearly there are some differences in appearance. The younger Eichmann (who is younger than 40 in all these pictures) clearly has light-coloured eyes (blue, grey, or perhaps green). The older "Eichmann's" eyes are not visible, due to the thick lensed glasses he is wearing.

There are some superficial similarities (both are slender men with prominent noses), but they don't strike me as the same person; the older Eichmann has

quite a 'Jewish look', a bit like a refined version of Woody Allen. Did they use an actor for the trial?

Hence my question: Would the real Eichmann please stand up? 
Ben Ner 
While writing this text, at the end of January 2011, and running between my partner, whom I was taking care of since he suffers from a chronic lung disease, and the wording of my Yiddish \& Avant-garde class final assignment, which will probably be about S. Ansky- Shloyme Zanvl Rappoport's pen name, and will mostly focus on the fact that while he was touring the small Jewish towns of east Europe as part of his ethnographic delegation project, he returned to his original name in order to blur his identity as a writer and publicist, I received an email from a man who called himself $\mathbf{E}$.

It is presumably the emotional stress that made me wonder, even before opening the email, about something that would seem irrational in any other circumstance; maybe that $\mathbf{E}$ stands for Eichmann, or Ansky, or maybe it stands for me, Ayellet.

In any case, this was its content: 
Ben Ner 
The relationship between the two worlds I belong to can be described as a section of an architectural plan, like the one I saw in my dream - I gazed from eternity at a piece of land that was spread out as if it were a cake; and heavy stairs, taller than man and hollow, crossed it diagonally. Little people clustered as if hiding in their own shadow, even though there was no light there, and nothing else except for dirt. The people themselves may have been made of dirt as well. I looked at these stairs from eternity wondering what they meant, when the memory of life above ground began to seep into me. I didn't feel suffocation, or helplessness, when the words slowly took shape and meaning until they crystalized into two whole sentences:

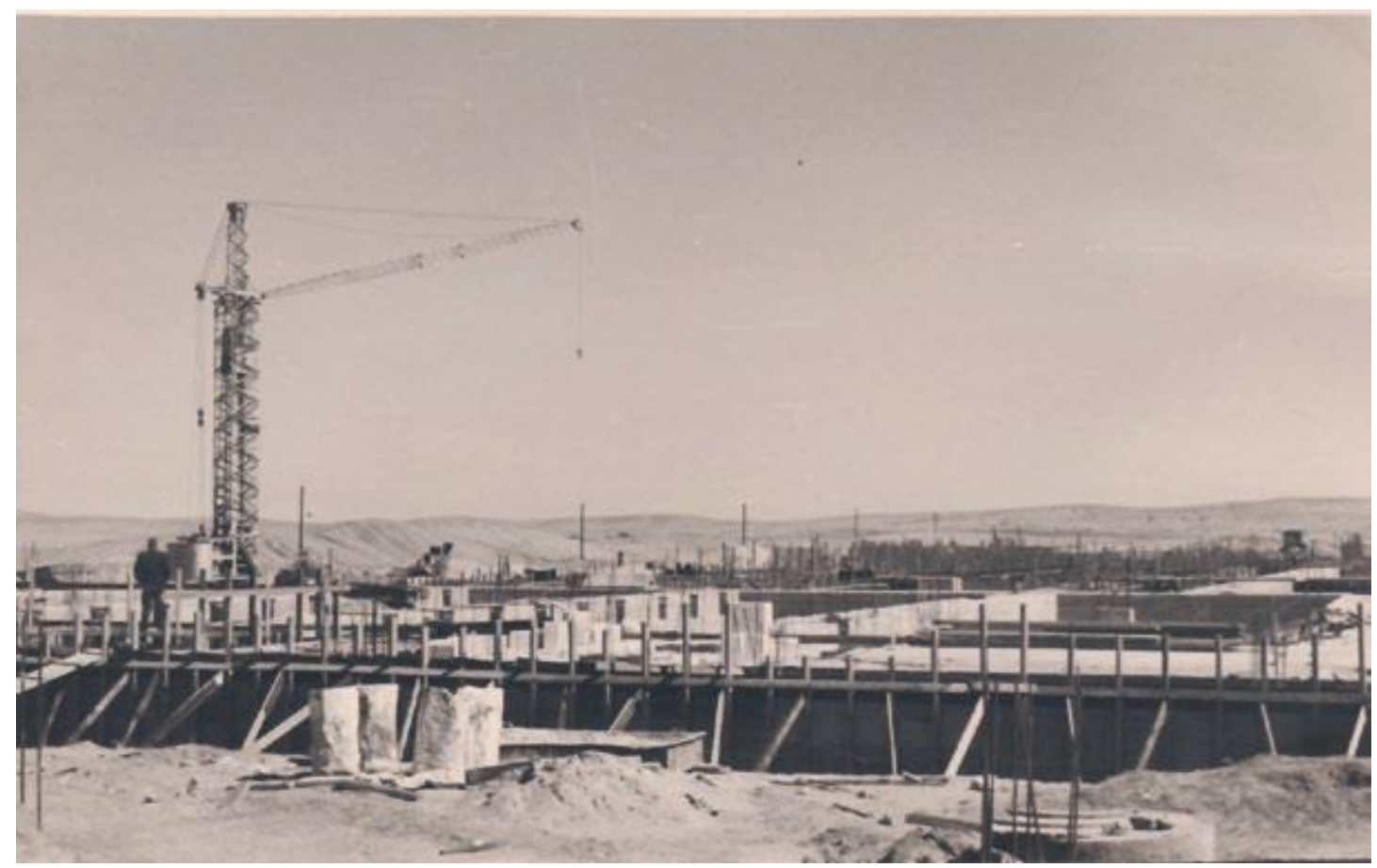

Fig 29: Author's Private Collection 


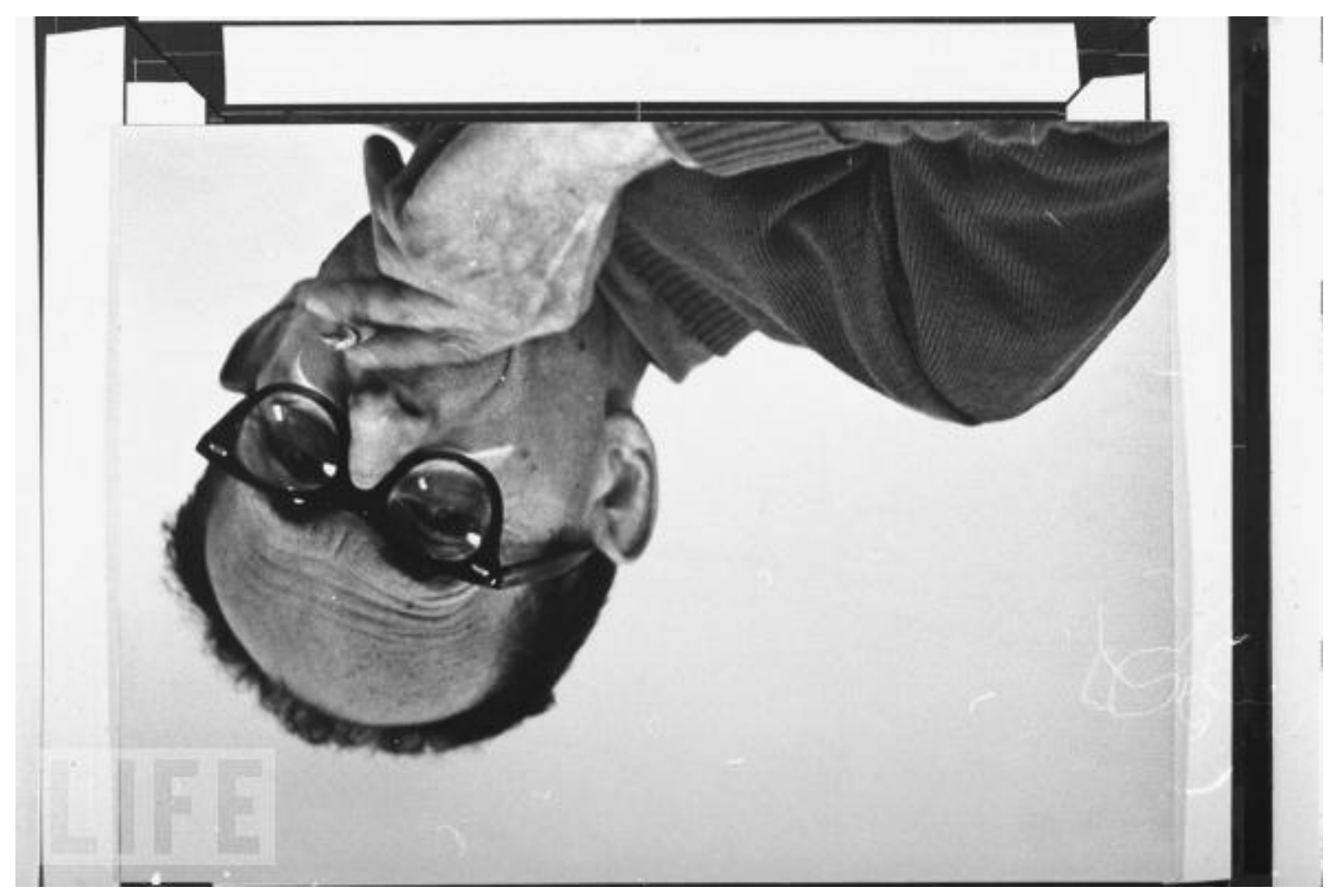

Fig 30: Courtesy of Yad Vashem

Die Treppe unter der Erde ermöglict die Sachen daruber Die Treppe unter der Erde erlauben die Ruckkehr ins Leben ${ }^{3}$ 
Persona Studies 2015, 1.2

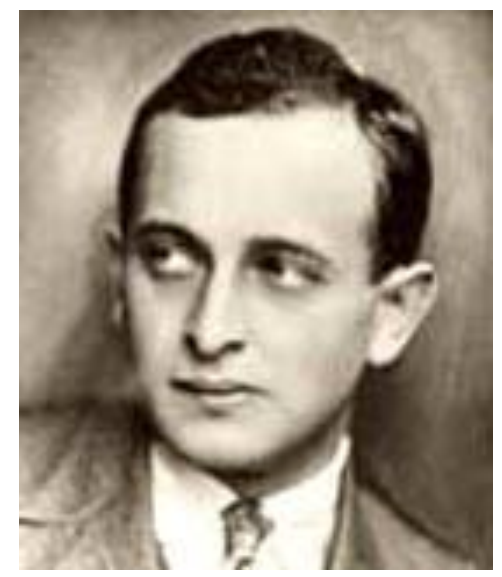

Ayellet Ben Ner is a graduate student in the Cultural Studies program at the Hebrew University in Jerusalem. Her research on the Israeli sex industry has informed both her creative and academic work. 